\title{
Late Disseminated Lyme Disease
}

National Cancer Institute

\section{Source}

National Cancer Institute. Late Disseminated Lyme Disease. NCI Thesaurus. Code C119038.

A late stage of Lyme disease that may present in untreated patients months to years after a tick bite manifested with intermittent bouts of arthralgia, arthritis and neurologic complaints. 